\title{
Pricing Information Goods: Free vs. Pay Content*
}

\author{
Marc BOURREAU ${ }^{\dagger}$ and Virginie LETHIAIS $\ddagger$
}

January 12,2005

\begin{abstract}
We analyze the incentives of a provider of information goods to offer a proportion of his product for free, when consumers are uncertain about the quality of the good. The provider faces the following trade-off. On the one hand, the free version of the product acts as a partially informative signal; the higher the proportion of the product which is offered for free, that is, the higher the size of the free version, the higher the probability that a consumer will discover the true quality of the good. On the other hand, the higher the size of the free version, the lower the willingness to pay for the remaining parts of the product. In a separating equilibrium, a low quality seller offers no free version and sets the perfect information optimal price, whereas a high quality seller offers a free version of his product to signal his quality. In a pooling equilibrium, both low and high quality sellers propose free versions of their products.

Keywords: Information goods; Internet; quality uncertainty; signalling.
\end{abstract}

${ }^{*}$ We would like to thank the Editor, Nicolas Curien, for very useful comments and suggestions. We would like also to thank Pierre-Jean Benghozi, Thierry Pénard, and Hervé Tanguy for their remarks.

†ENST, Paris and CREST-LEI, France. E-mail: marc.bourreau@enst.fr.

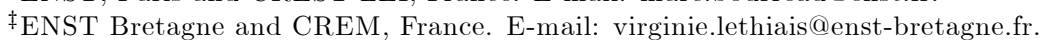




\section{Introduction}

Various types of information goods are available on the Internet: business news, general news, entertainment content, games, music, software, etc. At the beginning of the World Wide Web, most content was free, but since 2002, content providers have begun to charge their customers. According to a study of the Online publishers association (OPA, 2004), US consumers spent $\$ 1.56$ billion for online content in $2003,{ }^{1}$ a $18.8 \%$ increase over 2002.

The proportion of content offered for free varies a lot among content providers, as online press illustrates. At one extreme, some providers - like the Wall Street Journal online ${ }^{2}$ - offer only pay content, while at the other extreme, some providers offer only free content - as the French journal Libération did for a while. In between, online press firms offer both free and pay content. For example, the online journal Salon.com offers roughly half of its content for free, and the other half to its subscribers only ( $\$ 30$ per year). ${ }^{3}$ The French newspaper Le Monde provides some of its articles for free, but full access to content is available only to its subscribers. Combinations of free and pay content are also common for other types of content: degraded versions of software or video games can be downloaded for free, but the "full" version has to be purchased; excerpts of books or songs are also available at various online stores.

In this paper, we suggest that providing a proportion of an information good for free, that is, a "free version", aims at signalling the quality of the good, and we provide a theoretical framework which accounts for this signalling strategy. Of course, there might be other motivations to provide free content. In particular, firms could provide free content to attract large audiences, and generate advertising revenues. In this respect, the presence of advertising revenues explains why, following the recent slowdown of advertising expenditures on the Internet, some content providers, such as online newspapers or portals, have stopped to provide all content for free and started to charge for content. Nonetheless, these providers continue to provide both free and pay content.

Evaluation of quality before purchase is not a specific feature of the Internet. For instance, a sample of a beauty cream can be sent to potential consumers, or consumers can taste goods (like food) in supermarkets. However, evaluation of quality is much less costly both for the seller and the consumer on the Internet than on traditional markets.

We analyze the incentives of a provider of information goods to offer a free version of his product. Consumers are uncertain about the quality of the product (it is an "experience good"). The free version discloses information about the quality of the product to potential consumers, though it does not give perfect information. Furthermore, the higher the proportion of the product which is

\footnotetext{
${ }^{1}$ The OPA study excludes software.

${ }^{2}$ Headlines are free, but full articles can only be accessed by subscribers. The WSJ had 646,000 subscribers in June 2002. The price of the annual subscribtion to the online journal is $39 \$$ for subscribers to the print journal and $79 \$$ for non-subscribers.

${ }^{3}$ In 2002, Salon.com had only 39,500 subscribers for a total number of free users of 3,6 million. Free users have to watch an advertisement before reading the article.
} 
offered for free, that is, the higher the size of the free version, the more accurate is the signal about the quality of the product. Hence, the free version acts as a partially informative advertisement, since it allows consumers to discover the quality of the product with some probability.

We assume that consumers derive utility only from the first consumption of content, which implies that the higher the size of the free version, the lower the willingness to pay for the whole product. This is consistent with what we observe in markets for experience goods. For instance, in the press industry, readers with low willingness to pay for information tend to visit only free sites to get informed. For a book, the possibility to read the best excerpts can reduce the desire to read the whole book, hence the willingness to pay for it. This might be true for a film, too. In the software industry, every Internet user can download an "Acrobat reader" for free, and read pdf files using this software. However, Acrobat Reader does not allow users to create pdf files. One has to purchase the full "Acrobat" software for that. On the one hand, free access to one feature of the software ("read") may lead users to purchase the other feature ("write"), because they can evaluate the quality of the software. But on the other hand, it lowers the willingness to pay for the full set of features ("read"+"write").

Our paper is related to two strands of the economic literature. In media economics, free content ("programs") attracts audiences, which generates advertising revenues. A firm trades off between charging consumers and providing the good at a low price (maybe, even for free), in order to increase its audience, hence its advertising revenues (see Baye and Morgan [2000], Gabszewicz, Laussel and Sonnac [2004], Ferrando, Gabszewicz, Laussel and Sonnac [2004]). Lethiais [2001] also proposes a model with two sources of revenues - subscriptions and advertising revenues - and studies competition between service providers in the Internet. Barros, Kind, Nilssen and Sørgard [2002] construct a model of competition with advertiser-supported firms and ad-adverse consumers to analyze the incentives of Internet portals to form alliances with advertisers.

Our paper is also related to the economic literature about experience goods. Since disclosing information influences consumers purchase decisions, Grossman [1981], Crémer [1984], Lewis and Sappington [1994], Che [1996], and more recently, Gaudeul [2003], study whether firms should provide information to consumers about the goods prior to purchase. The decision of the firm to disclose information or not could also be a signal about the true quality of the firm. Milgrom [1981] and Okuno-Fujiwara et alii [1990] study the incentives for a firm to disclose information about its product in this context.

Advertising may not only reveal information about the good, but also convince consumers that the good is of high quality. Nelson [1970, 1974], Milgrom and Roberts [1986] and Kihlstrom and Riordan [1984] study the incentives of a monopolist to invest in non informative advertising. They show, in a context of repeated purchases, that, even if advertising reveals no information about the quality of the good, firms will advertise because it can modify buyers' perception about the quality of the good. Linnemer [2002] constructs a static model 
in which a monopolist can signal its quality through both its price and its investment in non informative advertising. He shows that, combined with price, advertising appears to be a useful signal of quality, and that a high quality firm makes greater profit than when only price is used to signal quality. Finally, advertising may also be informative: sellers can distribute free samples or propose demonstrations of their product. Moraga-González [2000] proposes a price signalling model with informative advertising, in which the seller chooses the proportion of the consumers to which he sends a signal, which is costly but completely informative. In his paper, the consumer receives two signals from the seller: the price of the good (which acts as a non informative signal) and the informative signal, which reveals the true quality of the good. He determines, in a static context, the conditions for advertising to arise in equilibrium.

In our paper, due to the two opposite effects of the free version on consumers' preferences, a high quality supplier faces the following trade-off. On the one hand, if he provides a larger proportion of free content, he signals the quality of its content more accurately. On the other hand, he reduces the proportion of the product, which is available to pay consumers only. Consumers also obtain information by observing the strategy of the seller. Indeed, consumers receive two signals: the price and the proportion of free content offered by the seller. We determine the perfect Bayesian equilibria of this game.

We show that a high quality seller provides a free version of his product in any separating equilibrium. Price is not sufficient to signal quality. This result contrasts with the result of Moraga-González [2000], who shows that informative advertising never occurs in any separating equilibrium, hence that price suffices to signal quality. In our model, even when consumers do not discover the true quality of the product, they observe the size of the free version offered by the seller. Therefore, a free version is not only an informative signal for some consumers, but also a signal of quality for all consumers. It differs from the model of Moraga-González, in which consumers who do not receive the signal do not know how many people have received it. This is why, in our model, a high quality seller has incentives to send this additional signal.

Moreover, we show that there is a unique separating equilibrium, which survives the intuitive criterion of Cho and Kreps [1987]. At this equilibrium, a low quality seller provides no free version and sets the perfect information optimal price, whereas a high quality seller offers a free version of his product to signal his quality and sets a price, which is lower than the perfect information optimal price. As a free version reduces the willingness to pay for the product, the high quality provider has to lower its price compared to the same setting with perfect information. An interesting implication of this result is that, if the quality of the good is high, uncertainty about the quality of content implies higher consumer surplus. Finally, at the pooling equilibria of the game, both types of sellers propose a free version of their products.

The paper is organized as follows. In Section 2, we begin by providing an empirical analysis of the strategies of online content suppliers. Our model is introduced in Section 3. We devote Section 4 to the determination of the 
demand for content. In Section 5, we determine the separating and pooling perfect Bayesian equilibria of the game. Finally, concluding remarks and possible extensions are presented in Section 6.

\section{Online content strategies}

Since the beginning of the Internet, some content has been offered for free. Various studies showed that consumers were reluctant to purchase online content, in particular because they felt that online payment was not secure, and that content was not attractive enough. ${ }^{4}$ Exceptions - like the Wall Street Journal online or software purchases - were rare.

However, since 2002, pay content has been developing on the Internet. A study of the Online publishers association (OPA, 2004) provides interesting information about the market for pay content, though it excludes software. According to this study, US consumers spent $\$ 1.56$ billion for online content in 2003, a $18.8 \%$ increase over 2002. Table 1 shows the online content spending by category of content. ${ }^{5}$ The top three categories in the OPA study are personals $\&$ dating, business content, and entertainment \& lifestyle. They account for $64 \%$ of all consumer spending.

\footnotetext{
${ }^{4}$ According the Pew Internet \& American Life Projet, in 2001, 17\% only of US Internet users were willing to purchase online content. The two main factors to persuade consumers to buy content online are higher security and better content (source: PaymentOne, 2003).

${ }^{5}$ Apart from software purchases, the OPA study also excludes the following categories: pornographic sites, gambling sites, illegal drug-related sites, Internet service providers, business services, online games with non-web browser-based interface.
} 


\begin{tabular}{|c|c|c|}
\hline Content category & Examples & $\begin{array}{l}\text { Spending in } 2003(\$ \\
\text { in millions })\end{array}$ \\
\hline Personals \& dating & Dating sites & 449.5 \\
\hline Business content & $\begin{array}{l}\text { Business news, busi- } \\
\text { ness research }\end{array}$ & 334.1 \\
\hline $\begin{array}{l}\text { Entertainment \& } \\
\text { lifestyle }\end{array}$ & $\begin{array}{l}\text { Digital multimedia, } \\
\text { erotica, humor }\end{array}$ & 214.0 \\
\hline Research & $\begin{array}{l}\text { Consumer research, } \\
\text { people research }\end{array}$ & 108.6 \\
\hline Personal growth & Motivational sites & 90.7 \\
\hline General news & $\begin{array}{l}\text { CNN.com, } \\
\text { LeMonde.fr }\end{array}$ & 87.5 \\
\hline $\begin{array}{l}\text { Community directo- } \\
\text { ries }\end{array}$ & $\begin{array}{l}\text { Virtual communities } \\
\text { like IMDB.com }\end{array}$ & 87.0 \\
\hline Games & $\begin{array}{l}\text { Games played } \\
\text { through web browsers }\end{array}$ & 73.0 \\
\hline Greeting cards & & 40.6 \\
\hline Sports & $\begin{array}{l}\text { Sports news, fantasy } \\
\text { sports, etc. }\end{array}$ & 38.2 \\
\hline Credit help & $\begin{array}{l}\text { Access to consumer } \\
\text { credit records }\end{array}$ & 36.6 \\
\hline Total & & 1559.8 \\
\hline
\end{tabular}

Table 1: content spending by category (source: OPA, 2004).

According to OPA (2003), 10.5\% of Internet users purchased online content in the first quarter of 2003. This is lower than the $17 \%$ of US Internet users who declared in 2001 that they were willing to purchase online content (according to Pew Internet \& American Life Project, 2001). Subscriptions represent $89 \%$ of total pay content revenues, with an average monthly subscription amount of $\$ 11$, whereas single payments represent only $11 \%$, with an average single payment amount of $\$ 21.7$.

Even though pay content is growing fast, most online content providers continue to offer free content. Below, we propose a few brief case studies, in which we analyze the motivations to propose free content.

\subsection{Online press}

In the online press, there is no "standard" business model. At one extreme, some providers offer all content for free. At the other extreme, some providers like the Wall Street Journal online - offer no free content. The French newspaper Libération is a good illustration of this variety of content strategies. When it started to operate online, Libération offered all content for free. In October 2001, the journal decided to charge for content; only breaking news were proposed for free. But in 2002, Libération changed its strategy again and offered all content for free. Finally, since 2004, Libération has been providing a selection of articles for free, whereas the newspaper can be purchased online in digital (pdf) format. 
When an online journal charges for content, the types of content which are sold to consumers varies a lot. Some newspapers, like Libération, only sell the newspaper in pdf format. The price of the pdf version is typically lower than the price of the paper version. For instance, another French journal, Le Monde, is sold 1 euro in pdf format against 1.20 euro for the paper version.

Other online journals propose "premium" (i.e., higher quality) content to their online subscribers. For instance, for 5 euros per month, Le Monde offers a digital version of the newspaper (in pdf or html format), e-mail alerts, weather information, specific multimedia content (photos, videos), etc. ${ }^{6}$ The online US journal Salon.com has adopted the opposite content strategy; the quality of free content is degraded by ads, pop ups and a slower download speed, compared to the site available to subscribers. Besides, Salon.com offers additional benefits to its subscribers, which are not available in the free site (like access to Wired magazine or audio downloads).

In these examples, free content, when available, has two different roles. First, it attracts audiences, and generates advertising revenues. Second, it allows consumers to evaluate the quality of content.

\subsection{Portals}

Portals offer a large range of services to Internet users, such as search tools, information services, webmail access, web pages, etc. Portals can be "independent" (like Yahoo! or MSN) or controlled by an Internet Service Provider (ISP). For instance, in France, Wanadoo.fr is the portal of the leading ISP, Wanadoo. Most of the revenues of portals are advertising revenues. However, some portals, like Yahoo.com, have begun to charge for content. For instance, in the fourth quarter of 2003, pay services represented $12.8 \%$ of Yahoo! total revenues (i.e., $\$ 85.2$ million out of a total revenue of $\$ 663.9$ million).

Some services are offered both in a free version and a vertically differentiated pay version. For instance, Yahoo.com offers a free mail account with Web access and a $4 \mathrm{Mb}$ storage, whereas its basic premium mail account service gives a $25 \mathrm{Mb}$ mailbox, POP access and other benefits for $\$ 19.79$ per year. Vertical differentiation between the free and the pay version increases the willingness to pay and softens the cannibalization between the two versions. Vertical differentiation occurs, either because the quality of the pay version is enhanced or because the quality of the free version is degraded. One example of quality degradation is Yahoo!'s home page service. In the free home page offer, Yahoo! incorporates ads to the user's web site. To get an ad-free site (and other benefits like a higher disk space for files, own domain name, etc.), one has to subscribe to the pay service (the basic offer is charged $\$ 8.95$ a month plus a setup fee of $\$ 15)$.

In these two examples, the free service allows consumers to evaluate the quality of the service; consumers with high willingness to pay for the enhanced

\footnotetext{
${ }^{6}$ The subscription to the online version of the journal is cheaper than the subscription to the paper version, which is greater than 15 euros per month.
} 
service can then switch to the premium service. Actually, most often, the services of Yahoo! are proposed in both a free and a pay version or a trial period is offered for free. Examples include: fantasy sports (a free version is available with less features), bill pay service (basic plan with a limited number of billers), Yahoo by phone (first month of service free).

Some portals of Internet Service Providers also propose pay services. For instance, in France, Wanadoo.fr proposes more than 100 pay services. ${ }^{7}$ Examples are: education services (English lessons, ...), entertainment services, information services, professional services. Most of these pay services are not available in a free basic version. ${ }^{8}$ In this case, the free services are used to attract audiences. Audiences generate advertising revenues, and some visitors might decide to purchase some of the pay services.

The portals of television channels in France have adopted the same strategy. They propose pay Internet services, which are related to popular television programs (like "Star Academy", and "Qui veut gagner des millions"). Free content serves to attract audiences for advertisers, and also to promote the programs and brand of the television channels.

\subsection{Financial information}

In 2001, in France, most online financial information services proposed only free services, and derived revenues from advertising. As the advertising market shrank, most sites switched to a mixed business model; basic services are still offered for free but consumers are charged for premium services. Basic financial information services target consumers with low willingness to pay and allow consumers with a high willingness to pay to evaluate the quality of service. Premium services offer a higher quality of service (real time information, personalized advice, etc.).

In 2002, one site, Serial-Traders, proposed only pay content. The price of the service was relatively low, compared to other sites (15 euros per month, compared to 90 euros per month for Boursorama). However, this site had the lowest number of subscribers in 2002 (10,000 subscribers, compared to 750,000 for Boursorama, for instance). It seems also that the quality of service was low; indeed some services proposed by Serial-Traders were offered for free by other sites. Eventually, Serial-Traders stopped its activity in April 2002.

\subsection{Software}

Some software producers offer free versions of their products on the Internet. The free version of a software might be a degraded version of the pay version, with less functionalities. For instance, Adobe's free Acrobat Reader has not the "write" functionality of Adobe's pay Acrobat. Another strategy consists in

\footnotetext{
${ }^{7}$ This service are available at http://servicesalacarte.wanadoo.fr.

${ }^{8}$ Some pay services (like weather information) are available both for free and as a paid service. But the free and the pay service do not appear on the same page, and Wanadoo does not indicate what is the differentiation between the two versions.
} 
offering a free trial version of the software, for a limited time (typically, one month). The same strategies are used by online games providers. Obviously, software firms provide free trial versions to allow potential consumers to try their products and evaluate their quality.

The case studies show that the proportion of the product offered for free is a strategic variable for the firms. Some content providers offer only free content/products, others propose only pay content/products, and, between these two extreme cases, some providers propose both free and pay content/products. In the following section, we construct a formal model which formalizes this strategic choice.

\section{The model}

\subsection{Supply}

A seller offers an information good, composed of different "elements", which can be consumed separately. For instance, the product of the seller could be an online newspaper composed of different articles, a book made of different chapters, a music CD with different music titles, or a software performing different functionalities or available at different time periods. For simplicity, we assume that the information good is composed of a continuum of "elements", and we normalize its total size to 1 .

We assume that each "element" has the same true quality, denoted $q$. The seller can be either of low type, $t=L$, or high type, $t=H$. A seller of type $L$ provides a low quality product $\left(q=q_{L}\right)$, and a seller of type $H$ provides a high quality product $\left(q=q_{H}\right)$, where $q_{H}>q_{L}>0$. The seller observes the true quality, but buyers don't. We assume further that $q_{H} \leq 2 q_{L}$, i.e., that the high quality is not too high relative to the low quality.

The seller chooses the size $\alpha \in[0,1]$ of the free version of his product, then chooses the price $p$ of the product. We denote $s_{t}$ a strategy of a seller of type $t=L, H$, that is, $s_{t}=\left(\alpha_{t}, p_{t}\right)$.

\subsection{Consumers}

Let $\mu$ denote the consumer belief about the quality of the product; consumers believe that quality is low with probability $\mu$ and that it is high with probability $1-\mu$, where $\mu \in[0,1]$. The expected quality of the product, conditional on the belief $\mu$, is $E_{\mu}(q)=\mu q_{L}+(1-\mu) q_{H}$. At the beginning of the game, consumers have the same prior belief, denoted by $\mu_{0}$.

Each consumer has a taste $\theta$ for quality. The taste parameter $\theta$ is uniformly distributed on the interval $[0,1]$. A consumer of type $\theta$ who pays price $p$ for a proportion $x$ of a product of expected quality $E_{\mu}(q)$ has an expected utility of

$$
E_{\mu}(U)=\theta E_{\mu}(q) x-p .
$$


If the true quality is $q_{t}$, he will receive utility of

$$
U=\theta q_{t} x-p .
$$

If available, consumers can use the free version of the product, at no cost, prior to deciding whether to purchase the product or not. When a consumer consumes the free version of the product, he obtains information about the quality of the product. Formally, he receives a signal $\sigma$, which can take on the following values: $\sigma=H$ (quality is high), $\sigma=L$ (quality is low), $\sigma=\emptyset$ (no information). Quality evaluation outcomes are governed by the following signal structure:

$$
\begin{aligned}
& \operatorname{Pr}\{L \mid q\}=\left\{\begin{array}{lll}
\gamma & \text { if } & q=q_{L} \\
0 & \text { if } & q=q_{H}
\end{array},\right. \\
& \operatorname{Pr}\{H \mid q\}=\left\{\begin{array}{lll}
0 & \text { if } & q=q_{L} \\
\gamma & \text { if } & q=q_{H}
\end{array},\right. \\
& \operatorname{Pr}\{\emptyset \mid q\}=1-\gamma .
\end{aligned}
$$

We assume that $\gamma$ is a function of $\alpha$, i.e., of the size of the free version. We also assume that $\gamma(\alpha) \in[0,1], \gamma(0)=0, \gamma(1)=1, \gamma^{\prime}(\alpha)>0$ and $\gamma^{\prime \prime}(\alpha) \leq 0$. A higher $\alpha$, hence a higher $\gamma$, corresponds to more precise information on the quality of the product. Consumers obtain no information when $\alpha=0$ (no free version) and perfect information when $\alpha=1$ (the product is free). The concavity of $\gamma(\alpha)$ means that consumers learn marginally less about the quality of the product as the size of the free version increases.

After receiving the signal $\sigma$, a consumer revises his belief according to the following rule: $\mu(\emptyset)=\mu_{0}, \mu(L)=1$ and $\mu(H)=0$.

\subsection{Timing}

The timing of the game is as follows:

1. Nature determines the type of the seller, $L$ or $H$.

2. The seller chooses the size of the free version, $\alpha \in[0,1]$, and the price of his product, $p \geq 0$.

3. Each consumer observes $\alpha$ and $p$, and revises his belief on quality. Then, he chooses whether or not to consume the free version. If he uses the free version, he receives a signal $\sigma$ and revises his belief accordingly.

4. Finally, each consumer decides whether or not to purchase the product.

We look at the perfect Bayesian equilibria (PBE) of this game. Remark that, in this setting, consumers obtain information about the quality of the product through two different channels. First, the strategy of the seller can convey information and signal his true quality. Second, consumers can obtain information by consuming the free version of the product. 


\section{Demand}

In this section, we determine the demand, conditional on a belief $\mu$. Assume that the seller provides both a free and a pay version of the product, that is, $\alpha \in(0,1)$. A consumer has four possible strategies:

- He can use the free version first, then

- if he anticipates a net gain from consuming the total product, he purchases the product (strategy FP),

- otherwise, he stops (strategy F).

- The consumer can purchase the product, without using the free version first (strategy P).

- The consumer can neither use the free version nor purchase the product (strategy N).

By eliminating the dominated strategies, we show the following result.

Lemma 1 The consumer always uses the free version of the product.

Proof. We show that there are only two non dominated strategies: F and FP.

First, note that strategy $\mathrm{F}$ dominates strategy N. Indeed, any consumer is better off consuming the free version (strategy $\mathrm{F}$ ) than consuming nothing (strategy $\mathrm{N}$ ), since with strategy $\mathrm{F}$ the consumer gets $E\left(U^{F}\right)=\theta \alpha E_{\mu}[q]$, which is strictly positive, whereas he gets $E\left(U^{N}\right)=0$ with strategy $\mathrm{N}$.

Second, to prove that strategy FP dominates strategy P, remark that strategy FP is equivalent to strategy $\mathrm{P}$ if the consumer does not modify his purchase decision after consuming the free version. However, if he discovers that quality is low, the consumer has the possibility of not purchasing the product, which shows that $E\left(U^{F P}\right) \geq E\left(U^{P}\right)$.

Lemma 1 implies that, when a free version is available, consumers always try to evaluate the quality of the product by using the free version. This has two implications. First, consumer choice is reduced to whether or not to purchase the product, after trying the free version. Second, given that there is a free version, a fraction of consumers will discover the true quality. Hence, we have to analyze the purchase decision, given the true quality, $q \cdot{ }^{9}$

\footnotetext{
${ }^{9}$ If there were an opportunity cost of using the free version, consumers with low taste for quality might not consume, and consumers with high taste for quality might purchase the product, without using the free version.
} 
Demand for a low quality provider To begin with, assume that the supplier provides low quality content, i.e., $q=q_{L}$. With probability $\gamma$, a consumer of type $\theta$ discovers that quality is low; he then purchases the product if and only if

$$
\theta(1-\alpha) q_{L}-p \geq 0
$$

Indeed, the consumer derives utility from consuming the remaining $1-\alpha$ parts of the product of quality $q_{L}$. Solving this condition for $\theta$ yields the equivalent condition $\theta \geq \theta_{L}^{*}$, where

$$
\theta_{L}^{*}=\frac{p}{(1-\alpha) q_{L}} .
$$

With probability $1-\gamma$ the consumer does not discover the true value of $q$; he decides to purchase the product if and only if $\theta(1-\alpha) E_{\mu}(q)-p \geq 0$. Solving this inequality for $\theta$ yields $\theta \geq \theta^{*}(\mu)$, where

$$
\theta^{*}(\mu)=\frac{p}{(1-\alpha) E_{\mu}(q)} .
$$

Note that $\theta^{*}(\mu) \leq \theta_{L}^{*}$, as $E_{\mu}(q) \geq q_{L}$. Besides, $\theta^{*}(\mu)$ increases with $\mu$, which means that, logically, the higher the belief that quality is low, the lower the demand.

To summarize, consumers of type $\theta$ such that $\theta \geq \theta_{L}^{*}$ purchase the product whether they discover the quality or not. Consumers of type $\theta$ such that $\theta \in$ $\left[\theta^{*}(\mu), \theta_{L}^{*}\right.$ ) purchase the product only if they do not discover that $q=q_{L}$ (which occurs with probability $1-\gamma$ ). Finally, consumers of type $\theta$ such that $\theta<\theta^{*}(\mu)$ do not purchase the product in any case. Therefore, when $q=q_{L}$, the demand for the product, conditional on the belief $\mu$, is given by

$$
D\left(q_{L}, \mu, \alpha, p\right)= \begin{cases}1-\theta^{*}(\mu)-\gamma(\alpha)\left(\theta_{L}^{*}-\theta^{*}(\mu)\right) & \text { if } \theta_{L}^{*}<1 \\ (1-\gamma(\alpha))\left(1-\theta^{*}(\mu)\right) & \text { if } \theta^{*}(\mu)<1<\theta_{L}^{*} . \\ 0 & \text { if } \quad \theta^{*}(\mu)>1\end{cases}
$$

The demand function shows that a low quality seller is harmed by the revelation of the true quality. The higher the size of the free version, $\alpha$, hence the higher $\gamma(\alpha)$, the lower the demand for the seller. Besides, demand decreases when $\mu$ increases.

Demand for a high quality provider Now suppose that $q=q_{H}$. With probability $\gamma$, a consumer of type $\theta$ discovers that $q=q_{H}$; he purchases the product if and only if $\theta(1-\alpha) q_{H}-p \geq 0$, or $\theta \geq \theta_{H}^{*}$, where

$$
\theta_{H}^{*}=\frac{p}{(1-\alpha) q_{H}} .
$$

With probability $1-\gamma$, the consumer does not discover the true value of $q$; he decides to purchase the product if and only if $\theta(1-\alpha) E_{\mu}(q)-p \geq 0$, i.e., if and only if $\theta \geq \theta^{*}(\mu)$. 
Note that $\theta_{H}^{*} \leq \theta^{*}(\mu)$, as $E_{\mu}(q) \leq q_{H}$. To summarize, consumers of type $\theta$ such that $\theta \geq \theta^{*}(\mu)$ purchase the product whether they discover the true quality or not. Consumers of type $\theta$ such that $\theta \in\left[\theta_{H}^{*}, \theta^{*}(\mu)\right)$ purchase the product only if they discover that $q=q_{H}$ (which occurs with probability $\gamma$ ). Finally, consumers of type $\theta$ such that $\theta<\theta_{H}^{*}$ do not purchase the product. Therefore, when $q=q_{H}$, the demand, conditional on the belief $\mu$, is given by

$$
D\left(q_{H}, \mu, \alpha, p\right)= \begin{cases}1-\theta^{*}(\mu)+\gamma(\alpha) \quad\left(\theta^{*}(\mu)-\theta_{H}^{*}\right) & \text { if } \theta^{*}(\mu) \leq 1 \\ \gamma(\alpha)\left(1-\theta_{H}^{*}\right) & \text { if } \theta^{*}(\mu)>1>\theta_{H}^{*} \\ 0 & \text { if } \quad \theta_{H}^{*}>1\end{cases}
$$

In contrast with a low quality seller, a high quality seller always benefits from the revelation of his true quality. Indeed, the higher $\alpha$, hence the higher $\gamma(\alpha)$, the higher the demand for the seller. However, when the belief, $\mu$, that quality is low increases, the demand for the product decreases.

\section{The equilibria}

In this section, we characterize the perfect Bayesian equilibria of the game. We start by computing the optimal price for a given belief, $\mu$, and a given size of the free version, $\alpha$. Then, we analyze the equilibrium with perfect information. Finally, we determine the separating and pooling perfect Bayesian equilibria of the game.

\subsection{Price determination}

To characterize the equilibria of the game, it is useful to determine the optimal price of the product, when the size $\alpha$ of the free version is given, and the belief $\mu$ is fixed. Let $\Pi(q, \mu, \alpha, p)$ denote the profit of a seller of true quality $q$. For $\alpha \in(0,1)$, the supplier has the following maximization problem,

$$
\max _{p} \Pi(q, \mu, \alpha, p)=p D(q, \mu, \alpha, p) .
$$

We distinguish two cases: $q=q_{L}$ and $q=q_{H}$.

Optimal price for a low quality provider $\left(q=q_{L}\right)$ We insert (1) into the maximization program (3) of the supplier. Solving this program yields the following result.

Lemma 2 If $q=q_{L}$ and $\alpha \in(0,1)$, the profit maximizing price is

$$
p_{\mu}^{*}\left(q_{L}, \alpha\right)=\frac{(1-\alpha) q_{L} E_{\mu}(q)}{2\left[q_{L}+\gamma\left(E_{\mu}(q)-q_{L}\right)\right]} .
$$

Proof. See Appendix 1. 
Replacing for $p_{\mu}^{*}\left(q_{L}, \alpha\right)$ in $\Pi\left(q_{L}, \mu, \alpha, p\right)$ gives the profit of the supplier,

$$
\Pi\left(q_{L}, \mu, \alpha, p_{\mu}^{*}\left(q_{L}, \alpha\right)\right)=\frac{(1-\alpha) E_{\mu}(q) q_{L}}{4\left[q_{L}+\gamma\left(E_{\mu}(q)-q_{L}\right)\right]} .
$$

Equation (4) shows that the larger the size of the free version, i.e., the higher $\alpha$, the lower the profit of the seller. Indeed, for a low quality seller, providing a free version has two negative effects on the willingness to pay. First, as we have already mentioned, providing free content reveals to some consumers that quality is low, hence the average expected quality decreases. Second, it reduces the proportion of the product, which is available to pay customers only.

Optimal price for a high quality provider $\left(q=q_{H}\right)$ When the true quality is high, demand is given by equation (2). We solve the maximization program of the supplier and we obtain the optimal price as a function of $\alpha$.

Lemma 3 If $q=q_{H}$ and $\alpha \in(0,1)$, the profit maximizing price is

$$
p_{\mu}^{*}\left(q_{H}, \alpha\right)=\frac{(1-\alpha) E_{\mu}(q) q_{H}}{2\left[q_{H}-\gamma\left(q_{H}-E_{\mu}(q)\right)\right]} .
$$

Proof. See Appendix 2.

Replacing for $p_{\mu}^{*}\left(q_{H}, \alpha\right)$ in $\Pi\left(q_{H}, \mu, p, \alpha\right)$, we obtain the profit of the supplier,

$$
\Pi\left(q_{H}, \mu, \alpha, p_{\mu}^{*}\left(q_{H}, \alpha\right)\right)=(1-\alpha) \frac{E_{\mu}(q) q_{H}}{4\left[q_{H}-\gamma\left(q_{H}-E_{\mu}(q)\right)\right]} .
$$

A larger $\alpha$ has two opposite effects on the willingness to pay. On the one hand, as above, a larger free version, that is, a higher $\alpha$, reduces the amount of the product available to pay customers only, which decreases the willingness to pay. This corresponds to the first term of the right-hand side in equation (5). On the other hand, trying the free version gives the information that quality is high with probability $\gamma(\alpha)$, which makes a fraction of consumers revise their beliefs, and increases the average willingness to pay.

\subsection{Perfect information}

For further comparison, we derive the equilibrium in perfect information. If quality is low, we have $\mu=1$. The size of the free version and the price which maximize profit are $\widehat{\alpha}_{L}=0$ and $\widehat{p}_{L}=q_{L} / 2$, respectively; the low quality seller obtains $\widehat{\pi}_{L}=q_{L} / 4$. If quality is high, we have $\mu=0$, and profit is maximized for $\widehat{\alpha}_{H}=0$ and $\widehat{p}_{H}=q_{H} / 2$; the high quality seller obtains $\widehat{\pi}_{H}=q_{H} / 4$.

Since consumers observe the quality of the product perfectly, a free version has no positive effect on the willingness to pay (through the revelation of the quality of the product); only its negative effect operates (it diminishes the proportion of product available to pay customers only). Hence, the seller offers no free version, and charges the profit maximizing price, which depends on the quality of content. 


\subsection{Separating equilibria}

Assume that there is a separating equilibrium, such that a low quality seller plays strategy $s_{L}$, a high quality seller plays strategy $s_{H}$, and $s_{L} \neq s_{H}$. Since he observes the strategy played by the seller, a consumer can infer whether it is a low or a high quality provider. Let $\mu(s)$ denote the revised belief after the observation of the strategy $s$ of the seller. We have therefore $\mu\left(s_{L}\right)=1$ and $\mu\left(s_{H}\right)=0$. We also denote $\Pi_{t}^{*}$ the equilibrium profit of a seller of type $t=L, H$.

Replacing for $\mu\left(s_{L}\right)=1$ into lemma 2 and equation (4) shows that a low quality seller sets necessarily $\alpha_{L}=0$ and $p_{L}=q_{L} / 2$, and obtains $\pi_{L}=\widehat{\pi}_{L}=$ $q_{L} / 4$. The high quality seller sets $s_{H}=\left(\alpha_{H}, p_{H}\right)$ and obtains a profit of $\pi_{H}=$ $p_{H} D\left(q_{H}, 0, \alpha_{H}, p_{H}\right)$.

Lemma 4 There is a multiplicity of separating equilibria. At any separating equilibrium, a seller of type $L$ plays his perfect information strategy, $\left(\widehat{\alpha}_{L}=0\right.$ and $\left.\widehat{p}_{L}=q_{L} / 2\right)$, and a seller of type $H$ plays a strategy $\left(\alpha_{H}, p_{H}\right)$, such that a seller of type $L$ has no incentives to play $\left(\alpha_{H}, p_{H}\right)$ and a seller of type $H$ has no incentives to play $\left(\widehat{\alpha}_{L}, \widehat{p}_{L}\right)$.

Proof. See Appendix 3 for a formal proof.

In a separating equilibrium, quality is perfectly inferred by consumers. A low quality seller acts as in perfect information. A high quality seller distorts his choice of price and size of free version, compared to perfect information. Indeed, suppose that the high quality seller plays the perfect information strategy $\left(\widehat{\alpha}_{H}, \widehat{p}_{H}\right)$. A low quality seller would gain from imitating a high quality seller, because if consumers believe that it is a high quality seller it obtains a profit of $q_{H} / 4$, which is higher than $\pi_{L}=q_{L} / 4$. Therefore, the equilibrium in perfect information is not a separating equilibrium of the game of imperfect information.

A more general question is whether a high quality seller can use his price only to separate from a low quality seller. In the following, we show that it is not the case.

Corollary 1 At a separating equilibrium, a high quality seller always proposes a free version of his product.

Proof. Suppose that there is a separating equilibrium, such that $\alpha_{H}=0$. The profit of the high quality seller, if he plays $\left(\alpha_{H}, p_{H}\right)$, is

$$
\pi\left(p_{H}\right)=p_{H} D\left(q_{H}, 0,0, p_{H}\right)=p_{H}\left[1-\frac{p_{H}}{q_{H}}\right] .
$$

Assume that $\pi\left(p_{H}\right)>\pi_{L}$, which means that the high quality seller has no incentive to mimic the low quality seller. If the low quality seller imitates the high quality seller, he obtains at best $\pi\left(p_{H}\right)$, since there is no free version and, hence everything is as if it were a high quality seller. As $\pi\left(p_{H}\right)>\pi_{L}$, the low quality seller has incentives to imitate the other type, which is not possible at 
a separating equilibrium. This proves that there is no separating equilibrium such that $\alpha_{H}=0$.

This corollary shows that, at any separating equilibrium, a high quality seller proposes a free version of his product to signal that his quality is high. This contrasts with the setting of Moraga-González [2000], in which informative advertising never occurs at any separating equilibrium. This is because price signals quality, and advertising is redundant, as consumers receive informative advertisements, but do not observe the advertising effort. In our paper, the free version is an informative signal in itself for some consumers, because it reveals the true quality of content with some probability. As it is observed by all consumers, it can also serve as a signal of high quality.

Though lemma 4 characterizes an infinity of separating equilibria, all of them are not equally convincing. Indeed, in a separating equilibrium, a high quality seller signals his quality by offering a free version, such that a low quality seller has no incentive to imitate his strategy. But since the profit of the high quality seller decreases with the size of the free version, a high quality seller obtains maximum profit when it offers the smallest free version, such that there is still separation at the equilibrium.

The "intuitive criterion" of Cho and Kreps (1987) helps us to formalize this intuition. The intuitive criterion requires the following. Assume that there is a deviation to an out-the-equilibrium strategy that is not in the interest of a low quality seller, but that there are beliefs that it could pay for a high quality seller. Then, consumers should believe that they face a high quality seller. Formally, for any out-the-equilibrium strategy, $s$, we have $\mu^{*}(s)=0$ if $\Pi\left(q_{H}, 0, s\right)>\Pi_{H}^{*}$ and $\Pi\left(q_{L}, 0, s\right)<\Pi_{L}^{*}$.

The only separating equilibrium that survives this criterion is such that the high quality seller sets $\alpha_{H}$ and $p_{H}$ so as to maximize his profit, given that a low quality seller has no incentive to imitate this strategy.

Proposition 1 The unique separating equilibrium, consistent with the intuitive criterion of Cho and Kreps (1987), is characterized by the following strategies:

$$
\begin{aligned}
& s_{H}=\left(\alpha_{H}^{*}, \frac{\left(1-\alpha_{H}^{*}\right) q_{H}}{2}\right), \\
& s_{L}=\left(0, \frac{q_{L}}{2}\right),
\end{aligned}
$$

where $\alpha_{H}^{*}$ is the smallest $\alpha_{H}$ that satisfies

$$
\alpha_{H} \geq 1-\frac{q_{L}}{q_{H}\left(1-\gamma\left(\alpha_{H}\right)\left(\frac{q_{H}}{q_{L}}-1\right)\right)} .
$$

Proof. Consider that the high quality seller chooses a size $\alpha_{H}>0$ for his free version and sets the optimum price given that separation occurs at the equilibrium, i.e., we have $p_{H}=\left(1-\alpha_{H}\right) q_{H} / 2$. The profit of the high quality seller, $\Pi_{H}\left(\alpha_{H}\right)=\left(1-\alpha_{H}\right) q_{H} / 4$, obviously decreases with $\alpha_{H}$. Therefore, the 
high quality seller sets the maximum $\alpha_{H}$ such that

$$
\Pi\left(q_{L}, 0, \alpha_{H},\left(1-\alpha_{H}\right) q_{H} / 2\right) \leq \pi_{L}
$$

still holds. Since we have

$$
\begin{aligned}
\Pi\left(q_{L}, 0, \alpha_{H}, p_{H}\right) & =p_{H} \times D\left(q_{L}, 0, \alpha_{H}, p_{H}\right) \\
& =\left(1-\alpha_{H}\right) \frac{q_{H}}{2} \times \frac{1}{2}\left[1-\gamma\left(\frac{q_{H}}{q_{L}}-1\right)\right],
\end{aligned}
$$

equation (6) is equivalent to

$$
\left(1-\alpha_{H}\right) \frac{q_{H}}{2} \times \frac{1}{2}\left[1-\gamma\left(\frac{q_{H}}{q_{L}}-1\right)\right] \leq q_{L} / 4 .
$$

As $\Pi_{H}\left(\alpha_{H}\right)$ decreases with $\alpha_{H}$, the solution $\alpha_{H}$ of the optimization problem is the smallest $\alpha_{H}$ that satisfies the following condition,

$$
\alpha_{H} \geq 1-\frac{q_{L}}{q_{H}\left(1-\gamma\left(\alpha_{H}\right)\left(\frac{q_{H}}{q_{L}}-1\right)\right)} .
$$

Finally, we check that this equilibrium exists. By construction, $\alpha_{H}$ is such that the low quality seller has no incentive to imitate the high quality seller. The high quality seller has no incentive to adopt the same strategy than the low quality seller if and only if

$$
\frac{\left(1-\alpha_{H}\right) q_{H}}{4}>\frac{q_{L}}{4}
$$

or

$$
\alpha_{H}>1-\frac{q_{L}}{q_{H}}
$$

which is true as $(7)$ holds. Therefore, the unique separating equilibrium is the one characterized by the proposition.

In the unique separating equilibrium, beliefs are given by $\mu^{*}\left(s_{L}\right)=1$ and $\mu^{*}\left(s_{H}\right)=0$, and for any other strategy $s \neq s_{L}, s_{H}, \mu^{*}(s)$ is sufficiently high such that neither type of seller gains from deviating to $s$.

In this equilibrium, the high quality seller offers a free version of his product to signal his quality. The price of a high quality seller is lower than under perfect information. This implies that consumers surplus is higher in the separating equilibrium of proposition 1 than under perfect information.

Illustration Assume that $\gamma(\alpha)=\alpha$, and let $\lambda=q_{H} / q_{L}$. The solution of (7) is

$$
\alpha_{H}^{*}=\frac{\lambda^{2}-\sqrt{\lambda^{4}-4 \lambda^{3}+8 \lambda^{2}-4 \lambda}}{2\left(\lambda^{2}-\lambda\right)} .
$$

We observe that $\alpha_{H}^{*}$ increases with $\lambda$, and that $\alpha_{H}^{*}$ goes to 0 when $\lambda$ goes to 1 , and $\alpha_{H}^{*}$ goes to 0.29 when $\lambda$ goes to 2 . Otherwise stated, the higher $q_{H}$ relative 
to $q_{L}$, the higher the size of the free version provided by the high quality seller. This is because the incentives of a low quality seller to mimic a high quality seller become stronger, hence a high quality seller has to provide a larger free version to separate.

\subsection{Pooling equilibria}

Now, we characterize the pooling equilibria of the game. In a pooling equilibrium, a low and a high quality supplier choose the same strategy $s^{*}=\left(\alpha^{*}, p^{*}\right)$, hence consumers are not able to revise their beliefs. A low quality supplier obtains $\Pi\left(q_{L}, \mu_{0}, \alpha^{*}, p^{*}\right)$, whereas a high quality supplier obtains $\Pi\left(q_{H}, \mu_{0}, \alpha^{*}, p^{*}\right)$. We assume that, for any strategy $s$ such that $s \neq s^{*}$, beliefs are given by $\mu(s)=1$.

This equilibrium is valid only if the low quality supplier has no incentive to deviate to his perfect information strategy, $\left(\widehat{\alpha}_{L}, \widehat{p}_{L}\right)$, i.e., only if

$$
\Pi\left(q_{L}, \mu_{0}, \alpha^{*}, p^{*}\right)>\widehat{\pi}_{L}=q_{L} / 4,
$$

and if a high quality seller has no incentive to deviate either, that is, if

$$
\Pi\left(q_{H}, \mu_{0}, \alpha^{*}, p^{*}\right)>\max _{\alpha, p} \Pi\left(q_{L}, 1, \alpha, p\right) .
$$

The intuitive criterion eliminates some pooling equilibria, but not necessarily all. A given $s^{*} \in S_{L}$ is not a pooling equilibrium anymore if there exists $s \neq s^{*}$, such that $\Pi\left(q_{H}, 0, s\right)>\Pi_{H}^{*}$ and $\Pi\left(q_{L}, 0, s\right)<\Pi_{L}^{*}$.

Proposition 2 In any pooling equilibrium, sellers propose a free version of their products.

Proof. Suppose that this is not the case, that is, there is a pooling equilibrium such that $\alpha^{*}=0$. A seller of high quality obtains

$$
p^{*}\left(1-\theta^{*}\left(\mu_{0}\right)\right)
$$

at the pooling equilibrium, with

$$
\theta^{*}\left(\mu_{0}\right)=\frac{p^{*}}{E_{\mu_{0}}(q)}
$$

and

$$
p^{*}\left(1-\theta^{*}(0)\right)
$$

if he deviates by offering a free version of size $\alpha$, with

$$
\theta^{*}(0)=\frac{p^{*}}{(1-\alpha) q_{H}} .
$$

If $\alpha$ is sufficiently small, then $\theta^{*}(0)<\theta^{*}\left(\mu_{0}\right)$, which implies that $(10)$ is greater than (9), hence that the high quality seller has an incentive to deviate from the 
equilibrium. This proves that, in any pooling equilibrium, sellers offer a free version of their products, i.e., $\alpha^{*}>0$.

To summarize, if we apply the intuitive criterion, the separating equilibrium of proposition 1 is the unique separating equilibrium of the game. A low quality seller proposes no free version and sets the perfect information optimum price, whereas a high quality seller proposes a free version to signal his (high) quality. The greater high quality relative to low quality, the higher the size of the free version. Besides, there are pooling equilibria, such that both types of sellers propose a free version of their product.

\section{Conclusion}

In this paper, we have studied the incentives of a seller of information goods to offer a proportion of his product for free, when consumers are uncertain about the quality of the product. We have shown that a unique separating equilibrium survives the intuitive criterion of Cho and Kreps (1987). In this equilibrium, a low quality provider offers no free version of his product and sets the perfect information optimal price, whereas a high quality content provider offers a free version to signal that he offers a high quality product, and sets a lower price than the optimal price in perfect information. We have also shown that price does not suffice to signal quality; offering a free version is necessary for a high quality seller to separate from a low quality seller. As the free version acts as a partially informative signal, the low quality seller has no incentive to imitate the high quality seller, as some consumers would discover that he provides a low quality product. There are multiple pooling equilibria of this game too, in which both types of sellers propose a free version of their products.

Our results seem to be consistent with what we observed in the online financial information market. On the one hand, Serial-Traders proposed a low quality service at a fair price. On the other hand, Boursorama offered a high quality service and a proportion of it for free, which allowed consumers to evaluate the quality of the service, and to be more informed when deciding whether to switch to the expensive "premium" service or not.

We analyzed only one aspect of the markets of information goods, namely, the "experience good" nature of information goods. Other features of markets of information goods, such as the importance of advertising revenues or the presence of network externalities, play also an important role, and might explain why some suppliers offer free versions of their products. For instance, an online journal could provide free content to obtain advertising revenues. Integrating one of these features to our model would probably lead to a wider range of strategies for each type of seller, and account for some sellers' behaviors that we outlined in the empirical study of section 2, but that do not appear as solutions of our model. 


\section{References}

[1] Barros, Pedro; Hans J. Kind, Tore Nilssen, and Lars Sørgard. 2002. "Media Competition When the Audience Dislikes Advertising: A Theory of Vertical Alliances on the Internet," work. paper, http://www.nhh.no/sam/cv/paper/barros-kind-nilssen-sorgardmediaportals.pdf.

[2] Baye, Michael R. and John Morgan. 2000. "A Simple Model of Advertising and Subscription Fees," Econ. Letters, 69, pp. 345-351.

[3] Che, Yeon-Koo. 1996. "Customer Return Policies for Experience Goods," J. Ind. Econ., 44, pp. 17-24.

[4] Cho, In-Koo and David M. Kreps. 1987. "Signaling Games and Stable Equilibria," Quart. J. Econ., 102, pp. 179-221.

[5] Crémer, Jacques. 1984. "On the Economics of Repeat Buying," RAND J. Econ., 15, pp. 396-403.

[6] Ferrando, Jorge; Jean Gabszewicz, Didier Laussel, and Nathalie Sonnac. 2004. "Two-sided Network Effects and Competition: An Application to Media Industries," work. paper, http://www.crest.fr/pageperso/lei/sonnac/FGLS.pdf.

[7] Gabszewicz, Jean; Didier Laussel, and Nathalie Sonnac. 2004. "Network Effect in the Press and Advertising Industries," work. paper, http://www.crest.fr/pageperso/lei/sonnac/network\%20effects.pdf.

[8] Gaudeul, Alexandre. $2003 . \quad$ "Shareware Competition: Selling an Experience," work. paper, http://econwpa.wustl.edu:80/eps/game/papers/0409/0409008.pdf.

[9] Lethiais, Virginie. 2001. "La Tarification des Services sur Internet: Intégration Verticale et Gratuité," Revue Econ., 52, pp. 39-56.

[10] Lewis, Tracy R. and David E. M. Sappington. 1994. "Supplying Information to Facilitate Price Discrimination," Int. Econ. Rev., 35, pp. 309-327.

[11] Linnemer, Laurent. 2002. "Price and Advertising as Signals of Quality when Some Consumers are Informed," Int. J. Ind. Organ., 20, pp. 931-947.

[12] Milgrom, Paul R. 1981. "Good News and Bad News: Representation Theorems and Applications," Bell J. Econ., 12, pp. 380-391.

[13] Milgrom, Paul R., and John Roberts. 1986, "Price and Advertising Signals of Product Quality," J. Polit. Economy, 94, pp. 796-821.

[14] Moraga-González, José Luis. 2000. "Quality Uncertainty and Informative Advertising," Int. J. Ind. Organ., 18, pp. 615-640. 
[15] Nelson, Phillip. 1970. "Information and Consumer Behaviour," J. Polit. Economy, 78, pp. 311-329.

[16] Nelson, Phillip. 1974. "Advertising as Information," J. Polit. Economy, 81, pp. 729-754.

[17] Okuno-Fujiwara, Masahiro; Andrew Postlewaite, and Kotaro Suzumura. 1990. "Strategic Information Revelation," Rev. Econ. Stud., 57, pp. 25-47.

[18] Online publishers association, 2003, Online pay content: Demographic and Usage Report, http://www.online-publishers.org/.

[19] Online publishers association, 2004, Online pay content: U.S. Market Spending Report, http://www.online-publishers.org/. 


\section{Appendix}

\subsection{Proof of lemma 2}

The demand, given by equation (1), is composed of two parts. We begin by optimizing the supplier profit on each demand segment. Then, we will show that only one local optimum is attained, hence it is the global optimum.

First, assume that $\theta_{L}^{*}<1$. The first-order condition for profit maximization gives the following local optimum,

$$
p_{L 1}^{*}=\frac{(1-\alpha) q_{L} E_{\mu}(q)}{2\left[q_{L}+\gamma\left(E_{\mu}(q)-q_{L}\right)\right]} .
$$

The second-order condition is always satisfied. This local maximum exists if and only if $\theta_{L}^{*}<1$. We show that this condition holds always. Inserting $p_{L 1}^{*}$ into $\theta_{L}^{*}$ shows that $\theta_{L}^{*}<1$ if and only if

$$
(1-2 \gamma) E_{\mu}(q)<2(1-\gamma) q_{L} .
$$

If $\gamma \geq 1 / 2$, this condition is always satisfied as the left-hand side is negative. When $\gamma<1 / 2$, condition (11) can be rewritten as

$$
E_{\mu}(q)<\frac{2(1-\gamma)}{1-2 \gamma} q_{L}
$$

which holds always, as $2(1-\gamma) /(1-2 \gamma) \geq 2$ when $\gamma \in[0,1 / 2), E_{\mu}(q) \leq q_{H}$ and $q_{H} \leq 2 q_{L}$.

Second, assume that $\theta_{L}^{*}>1>\theta^{*}$. The first-order condition for profit maximization gives the following local optimum,

$$
p_{L 2}^{*}=\frac{(1-\alpha) E_{\mu}(q)}{2} .
$$

The second-order condition is always satisfied. This local maximum exists if and only if $\theta^{*}<1$ and $\theta_{L}^{*}>1$. We show that this local optimum is not attained. By inserting $p_{L 2}^{*}$ into $\theta^{*}$, we find that $\theta^{*}=1 / 2$, hence $\theta^{*}<1$ holds always. But we have $\theta_{L}^{*}>1$ if and only if

$$
E_{\mu}(q)>2 q_{L}
$$

which is never satisfied as $E_{\mu}(q) \leq q_{H}$ and $q_{H} \leq 2 q_{L}$. Therefore, $p_{L 1}^{*}$ is the global maximum of the profit function.

\subsection{Proof of lemma 3}

The demand, given by equation (2), is composed of two parts. We begin by optimizing the supplier profit on each demand segment. First, assume that $\theta^{*} \leq 1$. The first-order condition for profit maximization gives

$$
p_{H 1}^{*}=\frac{(1-\alpha) E_{\mu}(q) q_{H}}{2\left[q_{H}-\gamma\left(q_{H}-E_{\mu}(q)\right)\right]} .
$$


The second-order condition is always satisfied. This local maximum exists if and only if $\theta^{*} \leq 1$. Inserting $p_{H 1}^{*}$ into $\theta^{*}$ shows that $\theta^{*} \leq 1$ if and only if

$$
E_{\mu}(q)>\left(1-\frac{1}{2 \gamma}\right) q_{H},
$$

which is always satisfied as $E_{\mu}(q) \geq q_{L} \geq q_{H} / 2$ and $1-1 / 2 \gamma<1 / 2$.

Second, assume that $\theta^{*}>1>\theta_{H}^{*}$. The first-order condition for profit maximization gives

$$
p_{H 2}^{*}=\frac{(1-\alpha) q_{H}}{2} .
$$

The second-order condition is always satisfied. This local maximum exists if and only if $\theta_{H}^{*}<1$ and $\theta^{*}>1$. But we have $\theta^{*}>1$ if and only if

$$
E_{\mu}(q)<\frac{q_{H}}{2},
$$

which never holds as $E_{\mu}(q) \geq q_{L} \geq q_{H} / 2$. Therefore, $p_{H 1}^{*}$ is the global optimum of the profit function.

\subsection{Proof of lemma 4}

Separation occurs at the equilibrium only if the low (resp., high) quality seller does not find it profitable to imitate the high (resp., low) quality seller.

First, consider that a low quality seller imitates the strategy of a high quality seller. In the best case for the low quality seller, consumers infer that the quality of the product is high, and the seller obtains a profit of $\Pi\left(q_{L}, 0, \alpha_{H}, p_{H}\right)$. The low quality seller has incentives to imitate the strategy of a high quality seller if he obtains a higher profit under the most favorable beliefs (that is, consumers believe that he is a high quality seller) than under the worst beliefs (that is, consumers believe that he is a low quality seller), which occurs when $\Pi\left(q_{L}, 0, \alpha_{H}, p_{H}\right) \geq \pi_{L}$. Otherwise stated, if a high quality seller plays strategy $s=(\alpha, p)$ such that $\Pi\left(q_{L}, 0, \alpha, p\right)<\pi_{L}$, a low quality seller has no incentive to imitate this strategy. We can now define $S_{L}$ as the set composed of the strategies of a high quality seller that a low quality has no incentive to imitate. We have

$$
S_{L}=\left\{s=(\alpha, p) \mid \Pi\left(q_{L}, 0, \alpha, p\right)<\pi_{L}\right\} .
$$

Now, consider the incentives for a high quality seller to imitate a low quality seller. If the high quality seller plays a strategy $(\alpha, p) \neq\left(\alpha_{H}, p_{H}\right)$, consumers infer, at worst, that he is a low quality seller and he obtains a profit of $\Pi\left(q_{H}, 1, \alpha, p\right)$. Let $S_{H}$ denote the set of strategies that give a high quality seller a higher profit under the most favorable beliefs than the maximum profit he can earn under the worst beliefs. We have

$$
S_{H}=\left\{s=(\alpha, p) \mid \Pi\left(q_{H}, 0, \alpha, p\right) \geq \max _{\alpha^{\prime}, p^{\prime}} \Pi\left(q_{H}, 1, \alpha^{\prime}, p^{\prime}\right)\right\} .
$$


The intersection of $S_{L}$ and $S_{H}, S_{L} \cap S_{H}$, is the set of strategies of a high quality seller, such that he has no incentive to deviate and that a low quality seller has no incentive to imitate.

We can now characterize the separating equilibria : a pair of strategies $\left\{\left(\alpha_{L}, p_{L}\right),\left(\alpha_{H}, p_{H}\right)\right\}$ is a separating equilibrium if $\left(\alpha_{L}, p_{L}\right)=\left(\widehat{\alpha}_{L}, \widehat{p}_{L}\right),\left(\alpha_{H}, p_{H}\right)$ belongs to $S_{L} \cap S_{H}$, and the beliefs are $\mu^{*}\left(\widehat{\alpha}_{L}, \widehat{p}_{L}\right)=1, \mu^{*}\left(\alpha_{H}, p_{H}\right)=0$, and for any other $(\alpha, p), \mu^{*}(\alpha, p)$ is sufficiently high such that neither type finds it profitable to play $(\alpha, p)$. 